\title{
Caring for people who inject drugs when they are admitted to hospital
}

\author{
Thomas D. Brothers MD, John Fraser MD, Duncan Webster MD
}

Cite as: CMAJ 2021 March 22;193:E423-4. doi: 10.1503/cmaj.202124

\section{1} Injection drug use and associated hospital admissions are increasingly common in Canada

The number of people who inject drugs in Canada increased from 130000 in 2011 to 171900 in 2016. ${ }^{1}$ Reported hospital admissions for patients with injection-associated infective endocarditis in Ontario increased 5-fold from 34 in 1997 to 176 in 2014. ${ }^{2}$

2

\section{People who inject drugs may not be comfortable disclosing} substance use

Clinicians should use a nonjudgmental approach to ask their patients about type, quantity and frequency of substance use. Illicit substance use is stigmatized and criminalized, which affects hospital care.,4 People who inject drugs ask for care that prioritizes trust and relationships, recognizes power imbalances and gives patients space. ${ }^{3}$

\section{Starting treatment for substance use disorders in hospital} improves outcomes

A randomized controlled trial ${ }^{5}$ and several cohort studies ${ }^{4,6}$ found inhospital initiation of opioid agonist treatment (e.g., buprenorphine or methadone) for opioid use disorder was associated with increased engagement with treatment and decreased readmissions or death, compared with outpatient referrals. All physicians can prescribe buprenorphine or methadone in hospital, although some provincial medical regulators require certification to initiate opioid agonist treatment. Addiction medicine consultation services can assist with complex diagnosis and management issues, including stimulant and polysubstance use disorders. ${ }^{4}$

Effectively treating opioid withdrawal reduces premature patient-initiated discharges against medical advice

People who inject drugs describe leaving hospital prematurely because of undertreated withdrawal and pain. ${ }^{3}$ Most people who inject drugs use opioids, ${ }^{1}$ and opioid medications are far more effective than nonopioids (e.g., clonidine) at relieving opioid withdrawal symptoms and facilitating hospital care. ${ }^{3,4}$ If patients decline opioid agonist treatment, physicians should consider frequent dosing of short-acting opioids (e.g., hydromorphone every $3 \mathrm{~h}$ ), titrated to symptom relief. ${ }^{4}$ Treating withdrawal or pain with opioids does not "worsen" addiction. Shared decision-making is essential. ${ }^{4}$

\section{Hospitals should offer harm reduction services}

Hospitals need to change traditional abstinence-only policies. ${ }^{4} \mathrm{Harm}$ reduction services, such as peer support, sterile injection equipment and disposal containers, take-home naloxone kits and supervised consumption facilities, should be offered by hospitals. When provided, these evidence-based services help reduce risks of infection and overdose among inpatients. ${ }^{4}$

\section{References}

1. Jacka B, Larney S, Degenhardt L, et al. Prevalence of injecting drug use and coverage of interventions to prevent HIV and hepatitis $C$ virus infection among people who inject drugs in Canada. Am J Public Health 2020; 110:45-50.

2. Coverdale N, Brogly S, Payne D, et al. Rates of infective endocarditis in substance use disorder and associated costs in Ontario. Can J Addict 2019;10:36-43.

3. McCall J, Pauly B. Sowing a seed of safety: providing culturally safe care in acute care settings for people who use drugs. J Mental Health Addic Nurs 2019;3:e1-7.

4. Allen D, Brouwer J, Dong K, et al. Management of substance use in acute care settings in Alberta: guidance document. Edmonton: Canadian Research Initiative on Substance Misuse (CRISM); 2020. Available: https:// crismprairies.ca/management-of-substance-use-in-acute -care-settings-in-alberta-guidance-document/ (accessed 2020 Dec. 4)

5. Liebschutz JM, Crooks D, Herman D, et al. Buprenorphine treatment for hospitalized, opioid-dependent patients: a randomized clinical trial. JAMA Intern Med 2014;174:1369-76.

6. Marks LR, Munigala S, Warren DK, et al. Addiction medicine consultations reduce readmission rates for patients with serious infections from opioid use disorder. Clin Infect Dis 2019;68:1935-7. 
Competing interests: Thomas Brothers is supported by the Dalhousie University Internal Medicine Research Foundation Fellowship, Killam Postgraduate Scholarship, Ross Stewart Smith Memorial Fellowship in Medical Research and Clinician Investigator Program Graduate Stipend (all from Dalhousie University Faculty of Medicine), a Canadian Institutes of Health Research Fellowship (CIHR-FRN no. 171259), and the Research in Addiction Medicine Scholars (RAMS) Program (National Institute on Drug Abuse; no. R25DA033211). No other competing interests were declared.

This article has been peer reviewed.

Affiliations: Division of General Internal Medicine and Clinician Investigator Program (Brothers), and Division of Infectious Diseases (Webster), Department of Medicine, Dalhousie University; Mobile Outreach Street
Health (Fraser), North End Community Health Centre, Halifax, NS; UCL Collaborative Centre for Inclusion Health (Brothers), Institute of Epidemiology \& Health Care, University College London, London, UK; Division of Infectious Diseases (Webster), Saint John Regional Hospital, Saint John, NB

Content licence: This is an Open Access article distributed in accordance with the terms of the Creative Commons Attribution (CC BY-NCND 4.0) licence, which permits use, distribution and reproduction in any medium, provided that the original publication is properly cited, the use is noncommercial (i.e., research or educational use), and no modifications or adaptations are made. See: https://creativecommons. org/licenses/by-nc-nd/4.0/

Correspondence to: Thomas Brothers, thomas.brothers@dal.ca 